* Notas y reseñas 



\title{
La locura artificial de Roberto Calasso. El discurso irracionalista frente a las ciencias
}

\begin{abstract}
Hay personas que actúan como si la razón fuera el aspecto menos relevante del ser humano. Es como si un soldado de guardia pensara: “¿De qué serviría mi rifle si una docena de enemigos me atacara? Voy a dejarlo a un lado y a fumar opio hasta adormecerme".
\end{abstract}

Victor Klemperer, I Will Bear Witness: A Diary of the Nazi Years, 1933-1941

Si accedemos a tomar prestado el título de una de las obras más logradas de Susan Sontag, La enfermedad y sus metáforas, podríamos llamar a los ensayos de Roberto Calasso "La locura y sus metáforas" en el mundo clásico y en el contemporáneo. Una de las obsesiones de Calasso es la relación entre la poesía y la locura. Lo mismo en su novela El loco impuro que en su edición del mítico libro del alemán Daniel Paul Scherber, Memorias de un enfermo de nervios; en La literatura y los dioses, y en La locura que viene de las ninfas, Calasso considera a la demencia una especie de don divino. ¿Hará falta aclarar que la locura clínica, las enfermedades que podemos ver en los hospitales psiquiátricos, nada tienen de poético ni de divinas? Más bien, cuando Calasso habla de locura alude a lo irracional que vive en cada uno de nosotros.

Luis Alberto Ayala Blanco, editor en español de algunas obras de Calasso y comentarista especializado de este autor italiano, apunta en una obradedicada a la defensa de lo irracional que: 
Debemos tener mucho cuidado en no confundir la locura provocada por los dioses con la locura "que se debe a enfermedades mentales". Esto es algo que los modernos no entienden, pues los inmortales hace mucho que se retiraron. $\mathrm{O}$ seguramente no se han retirado, sino que las vías de acceso que nos conducían a ellos están obstruidas por la lucha onanística que el individuo ha emprendido consigo mismo ( $E l$ silencio, 84).

Desde el siglo XVIII se ha perseguido ferozmente a lo irracional, y algunos psiquiatras se han dado a la tarea de rastrear las relaciones profundas, clínicas y filosóficas entre la "genialidad" artística y la demencia. Este tema ha sido motivo de una relectura atenta de la vida y la obra de William Blake, por ejemplo, quien en la década de 1790 encabezó un movimiento "contracultural" radical contra el racionalismo triunfante en Inglaterra. Ese movimiento dio un giro significativo al discurso científico, al pasar de una concepción aristotélica de la física al de la dinámica newtoniana.

La postura irracionalista de Calasso propone que la locura que sufren los artistas, en particular los poetas, es una forma premoderna de conocimiento. Varios de los escritores alemanes más sensibles, de la generación de 1770 a 1820, padecieron graves daños mentales: la carrera de Jacob Michael Lenz, importante dramaturgo y amigo cercano de Goethe, fue destruida por un trastorno psiquiátrico; Friedrich Hölderlin pasó las últimas décadas de su vida presa de una esquizofrenia casi total; Heinrich von Kleist acabó su vida con un pacto suicida; el poeta Clemens Brentano sufrió de melancolía religiosa y una depresión tan grande como la de Cowper. En todos estos casos y en algunos otros, el trabajo creativo más relevante estuvo acompañado de ataques de locura (el caso de los poetas ingleses Christopher Smart y John Clare fue diferente, pues escribieron sus obras más memorables dentro de una institución psiquiátrica).

Incluso para todos estos escritores - y para muchos de sus contemporáneos - la demencia fue a la vez un ideal y un antiideal, una especie de estado que trascendía la conciencia, en el que no sólo se escapaba de la obtusa racionalidad, a pesar del riesgo de que dicho estado se saliera de control. Para el artista romántico, la demencia fue más que un receso del pensamiento lógico; fue una forma de agudizar la intuición y la sensibilidad. En 1801, Hölderlin escribió: 
"Verdaderamente la exultante locura es la burla de la burla / cuando, de repente, el bardo se escucha en la noche sagrada" (apud Calasso, La literatura, 94).

A todo esto Roberto Calasso responde que hay un tipo de arrebato demencial —Platón lo definió como "locura divina"- el cual afecta a las mentes creativas. La lectura del escritor me parece una continuación de los temas que E. R. Dodds planteó en el clásico volumen Los griegos y lo irracional (1992). Con ese mismo espíritu, Calasso nos ofrece en su ensayo La locura que viene de las ninfas una visión peculiar del acceso esquizoide que padeció el historiador del arte alemán Aby Warburg (1866-1929), cuya labor en el campo de la estética lo llevó a estudiar la pervivencia del mundo pagano en el arte florentino, sobre todo de la iconografía de las ninfas en los grabados y las pinturas de Boticelli. Calasso se pregunta, ¿influyó en la demencia de Warburg el trabajo de indagar la vigencia de la imagen de las ninfas? El ensayista y novelista italiano así lo cree, piensa que el historiador sufrió un estado alterado, nada menos que la "locura que viene de las ninfas" (El loco, 68), a fin de cuentas una especie de trance psíquico y epistemológico, una revelación o epifanía de los dioses ocultos.

Evidentemente, esta tesis es inconsistente e inverosímil. ¿Pero qué atractivo tiene para la legión de lectores de Calasso? Sabemos que en 1920 Aby Warburg entró en un periodo de agresividad que lo hizo ingresar en la clínica psiquiátrica del doctor Luwdig Binswagner en Kreuzlingen, Suiza. La imaginación sobrecargada de Calasso lo lleva a afirmar que Warburg tuvo en este estado la revelación de su obra maestra, El ritual de la serpiente, un obsequio de la ninfa divina. Al final, Warburg se recuperó y escribió un libro de etnología comparativa entre el ritual de la serpiente de los indios pueblo, de Nuevo México, y la mitología judeocristiana. Si revisamos los estudios florentinos de Warburg veremos que sigue un procedimiento racional, lúcido y erudito. ¿Por qué entonces restarle méritos al raciocinio a favor de la irracionalidad?

No encuentro una sola razón de peso para el ninguneo gratuito al estudio científico del caso Warburg, salvo prolongar la moda de satanizar el pensamiento científico, ${ }^{1}$ sin darle el beneficio de la réplica.

${ }^{1}$ Por pensamiento científico me refiero a aquella actividad intelectual que reúne tres requisitos básicos: la objetividad, la universalidad y la inteligibilidad. 
Sobre todo a la luz del epistolario de Warburg con su médico, en donde no encontramos ni aun una remota alusión a la revelación divina que conceden las ninfas. Por lo menos así lo confirma la historia clínica de Warburg, que Calasso ni siquiera consideró consultar:

28 mayo de 1920

Después de cinco días tranquilos, los mejores que, según la enfermera, tuvo aquí en mucho tiempo, ayer, sin motivo aparente, cae repentinamente en un estado de excitación y delirio que casi había desaparecido; echa pestes contra todos, por ejemplo, contra el doctor Otto, con quien tomó el té; éste le habría dado tortas envenenadas de las que los demás no comían. Esta mañana se le quitaron las tres carteras [que paseaba de un lado a otro] por supuesto, maldice e insulta enormemente, pero en conjunto está más tranquilo que con ocasión de las anteriores incautaciones (Binswanger y Warburg, La curación infinita, 86).

Creo que en el caso de la locura divina que Calasso pone nuevamente a circular hay un timo consciente, o unas enormes ganas de creer en lo sobrenatural en detrimento del saber científico. Es como si un erudito se cansara de serlo y eligiera transformarse en chamán de la cultura alternativa. No veo empacho alguno, por ejemplo, en el estudio clínico de la locura debido a trastornos maniaco-depresivos presentado por la psiquiatra Kay Redfield (Marcados). La idea de ver en la locura la puerta a un mundo secreto es tentadora, pero encierra prejuicios enormes e injustificados contra el pensamiento racional. ${ }^{2}$

Entre otros aspectos del desorden depresivo de Warburg, su expediente confirma la existencia de ratos de lucidez que le permitieron escribir el libro El ritual de la serpiente, y que el tratamiento con base en fármacos reestableció su química cerebral permitiéndole con eltiempo recuperar la razón.

A la idea de que la irracionalidad y las pasiones nacen de la posesión de las ninfas contrapongo el estudio de la doctora Redfield sobre el trastorno maniaco-depresivo, una explicación científica a los

\footnotetext{
${ }^{2}$ Hay una larga tradición literaria de considerar la locura como una epifanía y al poeta como un visionario. En la modernidad, Charles Baudelaire la canonizó en su obra Los paraísos artificiales, y la han continuado cientos de poetas. En México contamos con dos ejemplos de poetas influidos por el surrealismo que defendían esta tesis como algo inobjetable: Octavio Paz y Luis Cardoza y Aragón.
} 
arrebatos delirantes de las mentes creativas. Tal vez se pierda el tono imaginativo, culto y retórico de Calasso sobre la locura, pero es una visión más concreta y verosímil de lo que sucede en la química cerebral de los artistas.

Redfield menciona que el erudito inglés Robert Burton, autor de La anatomía de la melancolía, como muchos de sus contemporáneos y seguidores en los siglos XVII y XVIII, opinaba que "todos los poetas están locos". Esta idea ha sido compartida por muchos desde entonces, pero los estudios clínicos demuestran que la relación - por más que a algunos les parezca atractiva, y sea o no acertada- entre la psicopatología y la expresión artística no existe, es decir, que la sensibilidad artística no depende de un temperamento melancólico. Por el contrario, en un padecimiento maniaco-depresivo o bipolar son numerosos los momentos de lucidez, e incluso el trastorno puede permanecer asintomático. La científica explica que:

No podemos eludir la explicación psiquiátrica que nos dice que en la relación entre psicología y el temperamento depresivo de algunos artistas muchos no se dan cuenta de las expresiones temperamentales más leves de la enfermedad o no saben que casi todos los que padecen la enfermedad maniaco-depresiva están, de hecho, la mayor parte del tiempo asintomáticos (esto es, están psicológicamente normales). Cuando quienes - aun los que generalmente están bien versados en psicología y medicina - piensan en la enfermedad maniaco-depresiva, tienden a imaginarse los antiguos pabellones de los manicomios y la enfermedad incurable y continua, y concluyen, con razón, que no es posible llevar a cabo ninguna obra creadora importante o sostenida en estas circunstancias. Sin embargo, la locura o la psicosis sólo es uno de los extremos del continuo maniaco-depresivo; casi ninguno de los que tienen esta enfermedad se vuelve loco. De igual manera, la obra inspirada o parcialmente ejecutada en un ligero estado de manía, incluso en estado psicótico, puede delinearse o corregirse mientras su creador está deprimido, y posteriormente darle el toque final cuando éste vuelve a la normalidad. Son la interacción, la tensión y la transición de los estados cambiantes del humor, al igual que el sostenimiento y la disciplina de los periodos de salud, los que tienen una importancia crítica, y son estas mismas tensiones y transiciones las que finalmente le dan poder al arte que nace de esta manera (Redfield, Marcados, 20). 
Luego entonces, el poeta no ingresa en un periodo fecundo al entrar en crisis psicológica; al contrario, es creativo gracias a los lapsos de lucidez. Creo que la explicación científica no denigra la condición humana ni impone su poder a las ciencias humanas; por el contrario, evidencia el desconocimiento mutuo entre el saber de la ciencia y el de las humanidades, que en las últimas décadas se ha hecho más profundo. Encuentro en un libro marginal de Ortega y Gasset una reflexión extensa sobre el dilema de la crisis de credibilidad de la gente de las humanidades en la ciencia.

El final de La locura que viene de las ninfas, un elogio a la manía, culmina con una cita de Sócrates, en donde afirma que la manía, la locura, viene de los dioses, mientras que sophrosyne viene de los hombres. Naturalmente, no es una defensa de los trastornos mentales, que nada tienen de divinos, sino de la forma como trabaja la mente creativa, la epifanía que se da cuando se llega a una conclusión, a una idea o tal vez al resolver un dilema existencial.

El asunto de fondo, y a fin de cuentas el tema de mi nota, es la falta de reflexión que impera en las ciencias humanas sobre los aportes de las ciencias duras - matemáticas, física, biología, etc. - Si uno curiosea por las bibliotecas encontrará un buen repertorio de libros escritos por científicos que buscan caminos para conciliar humanidades y ciencias. Y cabe preguntarse por qué no se ha superado el prejuicio del humanista ante la ciencia y la "terrible" amenaza de la racionalidad. Si preguntáramos a colegas humanistas sobre si se inclinan más por su preferencia por lo racional o lo irracional en su horizonte cultural, muchos se inclinarán por lo segundo, porque predomina la idea de que la ciencia es parte de un sistema represivo de las libertades individuales y es la cárcel de la imaginación. Pero esa respuesta muestra que buena parte de los humanistas tienen en mente al científico positivista, cerrado e intolerante, que dominó la escena cultural a finales del siglo XIX, y que prevalece una pobre idea de las obras científicas. Pero si tuviéramos un concepto amplio de la ciencia, si recapacitáramos en que nuestra vida sería impensable sin los avances de la medicina, por ejemplo, nuestra mente se abriría a la evidencia de que las ciencias duras comparten nuestro espacio vital de una manera determinante. Por mi parte, relaciono lo irracional con la violencia, la intolerancia, la razón de estado y un largo etcétera. Si 
el ser humano tiende a superar las adversidades es por su capacidad de raciocinio, no por sus raptos de irracionalidad.

Los nuevos caminos de las ciencias humanas, y en buena medida la antropología de la cultura, no pueden cerrarse a las aportaciones del pensamiento científico. Hace ya varios años, George Lakoff hablaba de la ciencia cognitiva como un nuevo campo del saber que incorporaba distintas disciplinas: la psicología, la linguística, la antropología, la filosofía y la computación. ${ }^{3}$ En su obra Women, Fire and Dangerous Things (1985), Lakoff estudia desde la ciencia cognoscitiva cuestiones relacionadas con las categorías mentales por medio de las cuales ordenamos el mundo y la razón misma. Encontrar una respuesta razonable y científica a los modelos mentales y culturales honra la inteligencia humana; en cambio, la explicación de la conducta como manifestación de lo irracional nos lleva a un callejón sin salida, en donde las ciencias humanas tienen la peor parte de un mundo dividido entre disciplinas exactas y humanidades.

La defensa de la irracionalidad entre los humanistas se ha vuelto un lugar común, y como tal no se somete a juicio en el medio académico. Hablo del gremio de críticos literarios académicos, cuya respuesta a la pregunta de si "creen en la racionalidad" es negativa. Creo que hacer alarde del "pensamiento" irracional implica un lamentable desconocimiento de los innegables aportes de la ciencia.

A favor de Calasso debo decir que sus estudios filológicos son muy sugerentes para rastrear la presencia de metáforas sagradas en poetas insospechados. Pero su teoría del conocimiento por medio del entusiasmo maniático tiene vacíos imposibles de salvar.

José Eduardo Serrato Córdova

\footnotetext{
${ }^{3}$ No puedo abundar en esta breve nota sobre las aportaciones de lo racional en las ciencias cognitivas, pero sí puedo proporcionar una lista para el curioso que quiera empezar a leer las obras básicas del pensamiento científico reciente. Yo soy un extraño bucle, de Douglas D. Hofstadter; El lenguaje de Dios, de Francis C. Colins; Yo, lo superfluo y el error, de Jorge Wagensberg.
} 


\section{REFERENCIAS}

Ayala Blanco, Luis Alberto, El silencio de los dioses, México, Sexto Piso, 2004.

BINSWANGer, Ludwig y Aby Warburg, La curación infinita. Historia clínica de Aby Warburg, trad. Nicolás Gelormini, Buenos Aires, Adriana Hidalgo Editora, 2005.

Calasso, Roberto, La literatura y los dioses, trad. Edgardo Dobry, Barcelona, Anagrama, 2001.

_- El loco impuro, trad. Teresa Ramírez Vadillo, México, Sexto Piso, 2003.

__ La locura que viene de las ninfas y otros ensayos, trad. Teresa Ramírez Vadillo, México, Sexto Piso, 2004.

Dawes, Robyn, La irracionalidad cotidiana. Cómo los pseudocientíficos, los lunáticos y el resto de nosotros fracasamos en pensar racionalmente, trad. María Teresa Ortega Sastriques, México, Océano, 2007.

DodDs, E. R., The Greeks and the Irrational [1951], Los Angeles, University of California Press, 1992.

LakofF, George, Women, Fire, and Dangerous Things. What Categories Reveal about the Mind, Chicago, Chicago University Press, 1985.

Ortega y Gasset, José, Historia como sistema y otros ensayos de filosofía [1941], Madrid, Alianza, 1981.

REDFIELD JAmison, Kay, Marcados con fuego. La enfermedad maniaco-depresiva y el temperamento artístico, trad. Angélica Bustamante de Simón, México, Fondo de Cultura Económica, 1998.

SCHREBer, Daniel Paul, Memorias de un enfermo de nervios. Ensayo introductorio de Roberto Calasso, trad. Ramón Alcalde, México, Sexto Piso, 2003.

WARBURG, Aby, El renacimiento del paganismo. Aportaciones a la historia del Renacimiento europeo, trad. Elena Sánchez y Felipe Pereda, Madrid, Alianza, 2005. 